\section{(6) OPEN ACCESS}

\title{
Emergency/disaster medical support in the restoration project for the Fukushima nuclear power plant accident
}

\author{
Naoto Morimura, ${ }^{1,2}$ Yasushi Asari, ${ }^{1}$ Yoshihiro Yamaguchi, ${ }^{1,2}$ Kazunari Asanuma, ${ }^{2}$ \\ Choichiro Tase, ${ }^{1,2}$ Tetsuya Sakamoto, ${ }^{1,2}$ Tohru Aruga, ${ }^{1,2}$ Members of the Japanese \\ Association for Acute Medicine, Emergency, Task Force on the Fukushima Nuclear \\ Power Plant Accident (JAAM-TF-FNPPA) ${ }^{1}$
}

\begin{abstract}
- Additional supplementary data are published online only. To view this file please visit the journal online (http://dx.doi. org/10.1136/emermed-2012201629).

${ }^{1}$ Japanese Association for Acute Medicine, Emergency Task Force on the Fukushima Nuclear Power Plant Accident, Tokyo, Japan

${ }^{2}$ Medical Response Team of the Off-site Center of the Fukushima Nuclear Power Plant, The Ministry of Health, Labour, and Welfare of Japan, Tokyo, Japan
\end{abstract}

\section{Correspondence to} Professor Naoto Morimura, Department of Emergency Medicine, Yokohama City University Graduate School of Medicine, Advanced Critical Care and Emergency Center, Yokohama City University Medical Center, 4-57

Urafunecho, Minami-ku, Yokohama 232-0024, Japan; molimula@yokohama-cu.ac.jp

Members who participated in the JAAM-TF-FNPPA are listed in the online Appendix.

Accepted 25 October 2012 Published Online First 26 November 2012

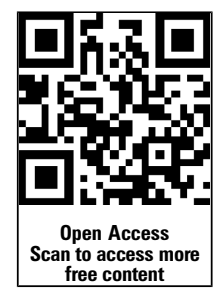

To cite: Morimura $N$, Asari $Y$, Yamaguchi $Y$, et al. Emerg Med J 2013;30: 997-1002.

\section{ABSTRACT}

The Fukushima Daiichi Nuclear Power Plant (1F) suffered a series of radiation accidents after the Great East Japan Earthquake on 11 March 2011. In a situation where halting or delaying restoration work was thought to translate directly into a very serious risk for the entire country, it was of the utmost importance to strengthen the emergency and disaster medical system in addition to radiation emergency medical care for staff at the frontlines working in an environment that posed a risk of radiation exposure and a large-scale secondary disaster. The Japanese Association for Acute Medicine (JAAM) launched the 'Emergency Task Force on the Fukushima Nuclear Power Plant Accident' and sent physicians to the local response headquarters. Thirty-four physicians were dispatched as disaster medical advisors, response guidelines in the event of multitudinous injury victims were created and revised and, along with execution of drills, coordination and advice was given on transport of patients. Forty-nine physicians acted as directing physicians, taking on the tasks of triage, initial treatment and decontamination. A total of 261 patients were attended to by the dispatched physicians. None of the eight patients with external contamination developed acute radiation syndrome. In an environment where the collaboration between organisations in the framework of a vertically bound government and multiple agencies and institutions was certainly not seamless, the participation of the JAAM as the medical academic organisation in the local system presented the opportunity to laterally integrate the physicians affiliated with the respective organisations from the perspective of specialisation.

\section{INTRODUCTION}

The Fukushima Daiichi Nuclear Power Plant (1F) suffered a series of radiation accidents after The Great East Japan Earthquake on 11 March 2011. The earthquake and the subsequent tsunami caused the failure of the containment cooling system of the reactors, leading to core meltdown and a hydrogen explosion within the reactors (12 March: No. 1 reactor; 14 March: No. 3 reactor; 15 March: No. 4 reactor) which then resulted in radiation leakage. Under the severe restrictions imposed at the site by radiation exposure, fires and explosions, the Fire Departments, Self-Defence Forces and the Tokyo Electric Power Company (TEPC) worked to mitigate the disaster.
In accordance with an initial response plan, a Declaration of a Nuclear Emergency Situation was intended to be issued in accordance with the Act on Special Measures Concerning Nuclear Emergency Preparedness immediately after the incident. In addition, the Fukushima Nuclear Emergency Response Centre, $5 \mathrm{~km}$ west of $1 \mathrm{~F}$, was intended to serve as the off-site centre (OFC) for the nuclear emergency response headquarters, the base on the frontlines for relevant ministries and government offices, local government, the TEPC and medical personnel. Furthermore, to strengthen the local radiation emergency medical system, Radiation Emergency Medical Assistant Teams (REMATs) are organised to be dispatched to the scene at the time of nuclear disaster and to give advice to the disaster countermeasures office of the local government. Moreover, the national radiation emergency medical system of Japan consists of networks of primary, secondary and tertiary radiation emergency medical centres designated by the national government. The primary radiation emergency medical centres provide decontamination and emergency treatment. The secondary radiation emergency medical centres accept radiation-exposed patients from the primary radiation emergency medical centres, measure radiation exposure levels of patients with a whole body counter and provide inpatient treatment. The roles of the tertiary radiation emergency medical centres are to provide instruction and advice on patient care and system protocols to the primary and secondary radiation emergency medical centres. There are two tertiary radiation emergency medical centres-Hiroshima University and the National Institute of Radiological Sciences (NIRS). In Fukushima Prefecture, five hospitals had been designated as primary radiation emergency medical centres and one hospital as a secondary radiation emergency medical centre.

On this occasion, a Declaration of a Nuclear Emergency Situation was issued in accordance with the above mentioned Act immediately after the earthquake. Until No. 1 reactor exploded on the afternoon of 12 March, the local primary radiation emergency medical centres provided decontamination and primary care, although their services were not sufficient. On the day after the accident, an REMAT from the NIRS was dispatched on a Self-Defence Force helicopter to the Fukushima 
Nuclear Emergency Response Centre, which was originally designated an OFC. However, because of the breakdown in infrastructure due to the loss of power caused by the earthquake, particularly for communication (telephone and internet), the REMAT confirmed that the centre could not function fully and the OFC function was transferred to the Fukushima Prefectural Government Office, $65 \mathrm{~km}$ northwest of 1F, on 15 March.

Furthermore, there were no functioning primary radiation emergency medical centres in the vicinity of $1 \mathrm{~F}$ so radiation emergency medical care was commenced on 13 March by a joint radiation emergency medical team consisting of the REMAT from the NIRS and Hiroshima University as the tertiary radiation emergency medical organisation. ${ }^{1}$ The Fukushima Municipal Hall next to the Fukushima Prefectural Government Office was designated as the radiation emergency medical headquarters, and a radiation emergency medical coordination committee was established with the added participation of the Fukushima Prefectural Social Welfare and Public Health Department and Fukushima Medical University Hospital (FMU Hsp). The joint radiation emergency medical team began medical treatment, conducting radiation surveys of residents evacuated from within the $20 \mathrm{~km}$ radius. However, there were many elderly people among the evacuated residents and patients in medical facilities and senior care facilities were among those residents left behind, making the response efforts difficult.

After the earthquake, more than 3000 people had been working daily within $1 \mathrm{~F}$ on the restoration project and, given the content of the work they were performing and the working environment, there continued to be the potential for radiation exposure as well as serious trauma, shock, wounds to the fingers and limbs, heat stroke and other common emergency disorders, in addition to the potential for mass casualties. In fact, the explosion of No. 1 reactor on 12 March left five people injured while the explosion of No. 3 reactor on 14 March left 11 people injured. Furthermore, on 24 March, three workers from the cooperating corporations were exposed to radiation when laying cables in No. 3 reactor. Meanwhile, the emergency transport system was extremely weak and, given the high level of ambient radiation, the operating policy was to not allow Fire Department ambulances, Self-Defence Force ambulances or helicopters within 1F. Patient transport vehicles from the TEPC were the only ones deployed to $1 \mathrm{~F} .1 \mathrm{~F}$ also had only one industrial physician from the electric power corporations working on site several days per week. Further, it took more than $1 \mathrm{~h}$ by car to the nearest emergency medical facility in Iwaki and more than $1 \mathrm{~h}$ to FMU Hsp, even if a helicopter was used to cover part of the distance. In addition to all of these issues, at the time of the earthquake it was uncertain what the risk for expansion of the evacuation zone would be and, if this were to happen, the options for the means of transport of the sick and injured as well as the receiving medical institutions would decrease and access would also be restricted (table 1). ${ }^{1}$

In a situation where halting or delaying restoration work was thought to translate directly into a risk for the entire country, it was of the utmost importance to strengthen the emergency and disaster medical system in addition to radiation emergency medical care for staff at the frontlines working in an environment that posed a risk for radiation exposure and a large-scale secondary disaster.

\section{BACKGROUND LEADING UP TO EMERGENCY/DISASTER MEDICAL SUPPORT}

The Japanese Association for Acute Medicine (JAAM) determined that support would be necessary until the accident reached some type of resolution and announced the launch of the 'Emergency Task Force on the Fukushima Nuclear Power Plant Accident (JAAM-ETF-FNPPA)' in an address given by the President on 28 March ('The Response to the Earthquake off the Pacific Coast of Tohoku by JAAM'). The address spoke of the need to send a team of physicians well versed in radiation and disaster medicine from among JAAM members in order to strengthen the system as well as the need for collaboration, coordination and medical integration of the various agencies such as the Fire Department, Self-Defence Force and the TEPC.

Upon a request from the director-general of the nuclear emergency response headquarters, the JAAM decided to send personnel as 'disaster medical advisors' to the OFC medical team

Table 1 Events during the initial 5 days after the earthquake ${ }^{1}$

\begin{tabular}{|c|c|c|}
\hline Date & Time & Event \\
\hline \multirow{3}{*}{$\begin{array}{l}11 \text { March } \\
2011\end{array}$} & $14: 46$ & The Great East Japan Earthquake occurred \\
\hline & $19: 03$ & $\begin{array}{l}\text { A Declaration of a Nuclear Emergency Situation was issued in accordance with the Act on Special Measures Concerning Nuclear Emergency } \\
\text { Preparedness }\end{array}$ \\
\hline & $21: 23$ & $\begin{array}{l}\text { The national government issued an evacuation order for residents within a } 2 \mathrm{~km} \text { radius of } 1 \mathrm{~F} \text { and an indoor evacuation order for those within a } \\
\text { radius of } 2-10 \mathrm{~km}\end{array}$ \\
\hline \multirow[t]{3}{*}{$\begin{array}{l}12 \text { March } \\
2011\end{array}$} & $5: 44$ & $\begin{array}{l}\text { An evacuation order was issued for } 48722 \text { residents within a } 10 \mathrm{~km} \text { radius. } \\
\text { An REMAT was dispatched to the OFC on a Self-Defence Force helicopter and confirmed that the communication system was inoperable }\end{array}$ \\
\hline & $15: 36$ & Hydrogen explosions occurred at No. 1 reactor. Four workers were injured \\
\hline & 18:25 & An evacuation order was issued for residents within a $20 \mathrm{~km}$ radius and emergency evacuation commenced using private vehicles and buses \\
\hline $\begin{array}{l}13 \text { March } \\
2011\end{array}$ & & $\begin{array}{l}\text { Coordination of evacuation of hospitalised patients and senior care facility residents within a } 20 \mathrm{~km} \text { radius commenced. Although the majority were } \\
\text { transferred out of Fukushima Prefecture, approximately } 840 \text { patients and residents were left within the } 20 \mathrm{~km} \text { radius at this point. } \\
\text { Within Fukushima City, a Radiation Emergency Medical Coordination Committee was established mainly by REMATs from the NIRS and Hiroshima } \\
\text { University as well as Fukushima Medical University and the Social Welfare and Public Health Department of Fukushima Prefectural Government }\end{array}$ \\
\hline \multirow{2}{*}{$\begin{array}{l}14 \text { March } \\
2011\end{array}$} & $0: 47$ & An emergency evacuation order was issued for hospitalised patients and senior care facility residents within the $20 \mathrm{~km}$ radius \\
\hline & 11:01 & Hydrogen explosions occurred at No. 3 reactor; 11 workers/Self-Defence Force members were injured \\
\hline \multirow{5}{*}{$\begin{array}{l}15 \text { March } \\
2011\end{array}$} & $6: 10$ & Hydrogen explosions occurred at No. 2 reactor \\
\hline & 9:40 & Hydrogen explosions occurred at No. 4 reactor \\
\hline & $11: 00$ & An indoor evacuation order was issued for residents within a $20-30 \mathrm{~km}$ radius \\
\hline & $15: 00$ & Evacuation of all residents within the $20 \mathrm{~km}$ radius was completed. \\
\hline & & The OFC function was transferred to Fukushima Prefectural Government Office in Fukushima City \\
\hline
\end{tabular}

NIRS, National Institute of Radiological Sciences; OFC, Off-Site Centre; REMAT, Radiation Emergency Medical Assistant Teams. 


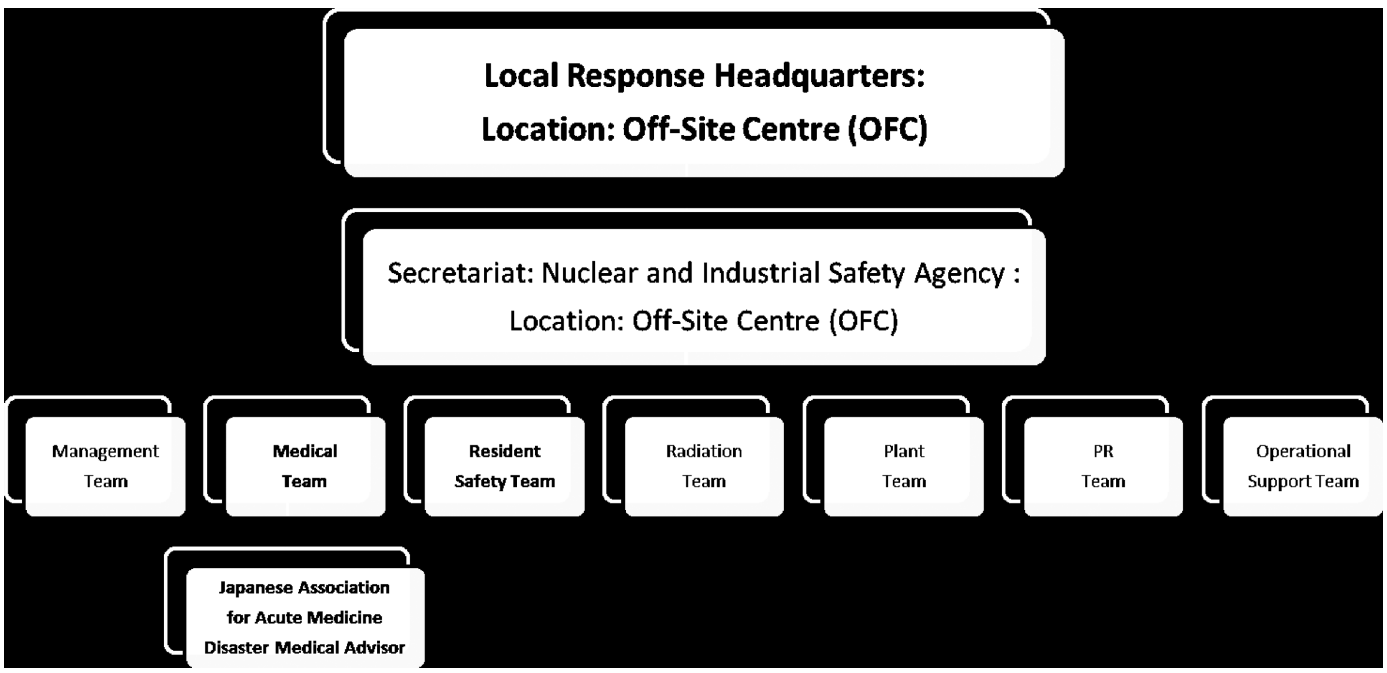

Figure 1 Organisational chart of the local response headquarters (Off-Site Centre).

of the local response headquarters. This medical team comprised personnel from the Ministry of Education, Culture, Sports, Science and Technology, the Fukushima Prefectural Government, the NIRS, Hiroshima University and JAAM under the direction of a team director sent from the Ministry of Health, Labour and Welfare (figure 1).

In addition, it was determined that a physician would be sent to direct and manage the medical team at J Village (JV), originally the national training centre for football, roughly $20 \mathrm{~km}$ from $1 \mathrm{~F}$, the medical frontline of the nuclear power plant restoration project and the temporary primary radiation emergency medical centre. The role of the JV directing physician was to conduct triage, decontamination and initial treatment and to connect patients with back-up medical facilities while working in close collaboration with the local response headquarters. This was the background leading to the deployment of one support person as a disaster medical advisor to the medical team at the local response headquarters within the Fukushima Prefectural Government Office from 4 April and one person as directing physician to the JV from 3 April.

\section{ACTIVITIES OF THE OFF-SITE CENTRE (OFC) MEDICAL TEAM}

A total of 34 supporting physicians were sent from the JAAM as OFC disaster medical advisors from 4 April to 31 August. Until 30 June, a system was used where members would rotate every 3 days to 1 week and, from 1 July, the position was filled by a member of the JAAM affiliated with the Fukushima Medical University Emergency Medicine Department and the JAAM gave support as needed in their absence. The job involved advising the medical team director with regard to all aspects of the work done by the medical team as well as drawing up, revising and training personnel on guidelines on how to respond in the event of multiple sick or injured patients on site and coordinating and advising the actual transport of emergency patients (box $1)$.

The disaster medical advisors successively sent to the OFC medical team first set to work on revising the previous 'Response Flow of Communication in the Event of Sick or Injured Patients' to make it more practically effective. As part of this process, the advisors confirmed the status of treatment at surrounding medical facilities while collaborating closely with FMU Hsp to determine the medical facilities to which patients should be transported. They also coordinated the Fire and Disaster Management Agency, FMU Hsp, the Self-Defence Forces and the Japan Coast Guard with regard to the use of ambulances and helicopters and engaged in discussions with the related organisations regarding the radiation emergency medical response. Simulation training to put the flow into operation was conducted on 7 and 21 April and the advisors presided over the proceedings of the web meetings in which the respective related medical organisations participated daily. After exchanging opinions, minor revisions were repeatedly made to account for the use of local Fire Department resources, the state of medical facilities and the support system as the flow was put into

\section{Box 1 Role of the Off-Site Centre disaster medical} advisor

1. Advise the medical team director as needed on all aspects of the emergency/disaster medical system.

2. Formulate a response plan in the event of patients suffering from radiation exposure and revise as needed through training sessions and simulations to ensure the effectiveness of the plan in spite of changes in the situation of the medical facility or transport facility or changes in the environment.

3. Determine the transport method and destination for patients suffering from radiation exposure from the Fukushima Daiichi Power Plant in accordance with the 'Response Flow of Communication in the Event of Sick or Injured Patients'.

4. Compile the contents of the proceedings of web meetings of relevant medical personnel, consider the issues and propose solutions as appropriate.

5. Periodically report on the content of activities and changes in the action plan to the Association headquarters and consider the medical matters that the Association should be proposing and collect relevant materials.

6. Give advice regarding the radiation level screening process at the prefectural emergency response headquarters for 'temporary entry' zones. 
operation. The actual means of transport and time was recorded and used as the basis for revisions.

The OFC would then coordinate with transporters such as the Self-Defence Force, Fire Department and the TEPC vehicles. It would also coordinate the receiving medical facility and report the time the patients would be arriving. A flow was also formulated for the transport of the sick and injured and destinations based on the severity of the patient's condition and the level of radiation exposure.

The practice of daily communication with each relevant organisation at set times was also put in place from late April to build a system for sharing information accurately and promptly, which is essential to the smoothness of the response to an emergency or disaster. Specifically, regular communication was made each morning from the OFC medical team to the related organisations via fax, MCA wireless, cell phones and land lines.

In addition, to prevent heat stroke among the workers in an environment with high temperatures and high humidity, site managers provided workers with materials informing them of methods of prevention, environments that lead to heat stroke and the initial symptoms.

\section{ACTIVITIES OF THE JV MEDICAL TEAM}

From 18 March to 2 April, in response to a request from the Tokyo Fire Department and later from the Fire and Disaster Management Agency and from 3 April to 31 August officially from the JAAM, a total of 49 members took on the role of directing physicians in the JV medical team. These were specialists in emergency medicine who were well versed in the treatment of radiation exposure (instructors of radiation exposure workshops or those who had completed a high-level course on the subject). The JV Medical Center was established as the base for operations within the grounds and a route was determined for transporting patients. An operating system for responding to patients with radiation exposure and to multiple patients was built up through training sessions and by responding to actual emergency patients from $1 \mathrm{~F}, \mathrm{JV}$ and the surrounding area (figure 2).

In JV, the number of outpatient examinations conducted by the TEPC hospital physicians during this same period was 1694 , of which the largest number was 788 patients with colds.

From 1 July the TEPC Fukushima Daiichi Nuclear Power Plant Emergency Medical System Network was created with Hiroshima University as the secretariat. Due to the fact that a physician was constantly stationed within the Daiichi Nuclear Power Plant (5/6 ER) and progress made in restoration work led to a reduced risk of multiple sick or injured due to an explosion, from 31 August all JV directing physician activities were concluded. From September, JV medical team activities were continued with the deployment of physicians from the University of Occupational and Environmental Health, Japan as well as the Rosai Hospital. On 6 December the JV Medical Center was officially approved by the prefecture as a clinic, and it continues to maintain its treatment system.

\section{RADIATION ENVIRONMENT OF THE MEDICAL TEAM}

The temporal increase in air dose rate did not show a concentric pattern, but it has been revealed that contamination was widespread northwest of $1 \mathrm{~F}^{2}{ }^{3}$ In Fukushima City, located approximately $50-60 \mathrm{~km}$ northwest of $1 \mathrm{~F}$, the air dose rate was $\leq 0.1 \mu \mathrm{Sv} / \mathrm{h}$ at $09: 00$ on $15 \mathrm{March}$, increased rapidly around 15:00 on the same day and exceeded $24 \mu \mathrm{Sv} / \mathrm{h}$ at 18:00. Because it snowed overnight on $15 \mathrm{March}$, the rate remained at relatively high levels of $5-10 \mu \mathrm{Sv} / \mathrm{h}$ before gradually decreasing. A few weeks had elapsed since the disaster when the JV medical team provided medical assistance, and the JV Medical Center was located south-southwest of $1 \mathrm{~F}$; consequently, the dose rate measured outside the JV Medical Center was low at approximately $1 \mu \mathrm{Sv} / \mathrm{h}$. According to the data obtained on 5 April, the air dose rates were $1-2 \mu \mathrm{Sv} / \mathrm{h}$ at the front of the JV Medical

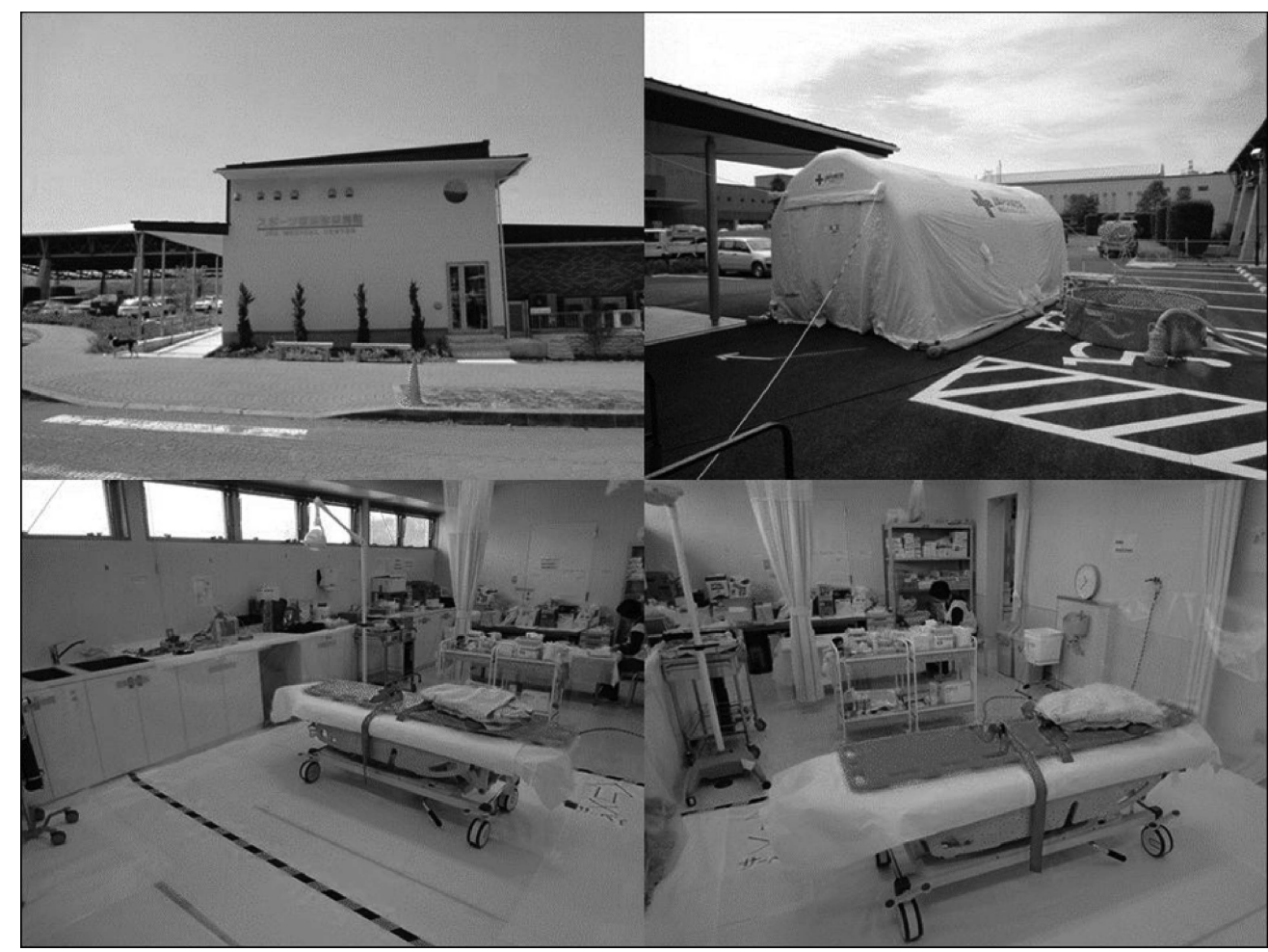

Figure 2 JV Medical Center (top left), decontamination tent (top right), examination rooms (bottom right and left). 
Table 2 Diagnosis and outcome of patients

\begin{tabular}{|c|c|c|c|c|c|c|}
\hline \multirow[b]{2}{*}{ Disorders } & \multirow[b]{2}{*}{ No. of patients } & \multicolumn{4}{|c|}{ Outcome } & \multirow[b]{2}{*}{ No. and type of immediate life-saving intervention } \\
\hline & & Home & Admission & Dead & Unknown & \\
\hline Trauma & 118 & 85 & 10 & $2^{*}$ & 21 & 2 (TAE for haemorrhagic shock due to pelvic fracture and splenic injury) \\
\hline Common cold, fatigue & 77 & 72 & 1 & 0 & 4 & 0 \\
\hline Heat stroke & 44 & 39 & 1 & 0 & 4 & 0 \\
\hline External contamination & 8 & 5 & 3 & 0 & 0 & 0 \\
\hline ACS & 5 & 2 & 2 & 1 & 0 & 3 (PCI for 2 and CPR for 1 ) \\
\hline Convulsion, LOC & 5 & 1 & 2 & 0 & 2 & 0 \\
\hline CVD & 2 & 0 & 2 & 0 & 0 & Unknown \\
\hline Septic shock & 1 & 0 & 0 & 1 & 0 & Unknown \\
\hline Asthma & 1 & 0 & 1 & 0 & 0 & 0 \\
\hline
\end{tabular}

Center and $6-8 \mu \mathrm{Sv} / \mathrm{h}$ in the parking area dedicated for vehicles used to commute to $1 \mathrm{~F}$. The radiation exposure levels of dispatched doctors were $25.5 \mu \mathrm{Sv}$ for $114 \mathrm{~h}$ from 3 to 7 April and $21.9 \mu \mathrm{Sv}$ for $84 \mathrm{~h}$ from 15 to 18 April (all measures obtained with a Toshiba PM-1621).

\section{PATIENTS}

From 11 March to 16 December the total number of sick or injured patients from $1 \mathrm{~F}, 2 \mathrm{~F}$ and the surrounding area was 261. The mean \pm SD age was $43 \pm 13$ years (range 19-71) and all were men. One hundred and eighteen had external injuries, 44 had heat stroke, 8 had external contamination/suspected of external contamination, 5 had loss of consciousness, 5 had acute coronary syndrome/arrhythmia, 2 had stroke, 1 had septic shock, 1 had asthma and 77 had other conditions (eg, discomfort, fatigue, colds; table 2). A total of 242 cases were reported from $1 \mathrm{~F}, 5$ were reported while moving between $1 \mathrm{~F}$ and JV, 3 were reported from $2 \mathrm{~F}$ and 11 were reported from other surrounding areas.

None of the eight patients with external contamination or suspected of external contamination developed acute radiation syndrome. According to the TEPC, there were six workers whose radiation exposure levels exceeded $250 \mathrm{mSv}$, the legal limit in Japan for radiation exposure during approximately 1 year of emergency work (since February 2012). Their levels ranged from a maximum of $678.8 \mathrm{mSv}$ to a minimum of $310.97 \mathrm{mSv}$. It is speculated that these workers suffered from internal exposure to iodine-131 and they were followed up with detailed examinations at the NIRS (table 3).

Of the 242 cases from 1F, 150 were kept for observation within the $1 \mathrm{~F}$ earthquake absorbing wing or the $5 / 6 \mathrm{ER}$ or had completed examination after treatment, 58 cases were transported to JV, 36 of whom were transported to medical facilities. In addition, 31 patients were transported directly to medical facilities without going through JV. With regard to the mode of transport, of the 67 patients transported from $1 \mathrm{~F}$ to medical facilities, 44 were transported by Fire Department ambulances, 6 were transported by emergency medical helicopter, 14 were transported by general use vehicles or industrial transport vehicles and no mode of transport was recorded for 3 patients (figure 3).

Of the 79 patients transported to medical facilities between 11 March and 16 December, 32 were transported to Iwaki Kyouritsu Hospital, 14 to Fukushima Medical University Hospital, 10 to Fukushima Rosai Hospital, 13 to the $2 \mathrm{~F}$ clinic (only in the initial stages after the earthquake) and 10 patients were transported to other facilities. Four patients died; two were missing on the day of the earthquake and two died from cardiac arrest due to acute coronary syndrome and sepsis.

Most of the means of transport to medical facilities involved the use of the TEPC industrial transport vehicles to JV followed by a rendezvous with a Fire Department ambulance sent from the nearest Fire Department or with an emergency medical helicopter at a sports ground near JV. As the time between a request to the nearest Fire Department for an ambulance and its arrival at JV was 40-50 min, the OFC disaster medical advisor was often forced to decide between an ambulance or emergency medical helicopter at the time the first report was made from $1 \mathrm{~F}$, complicating operations. However, after 10 June when an ambulance was allocated to the Naraha Branch of the Tomioka Fire Department Futaba Regional Municipal Cooperative located $3 \mathrm{~min}$ by car from JV, there was more time for the exchange of information between $1 \mathrm{~F}$, JV and OFC, simplifying the task of selecting the most appropriate mode of transport.

The disaster medical advisor supervised the coordination of transport for 66 patients (mean \pm SD age $44 \pm 12$ years, range 20-64, all men) and, of these, 45 were taken by emergency transport to hospitals ( 35 by Fire Department ambulance, 9 by emergency medical helicopter and 1 by a general use vehicle).

\section{DISCUSSION}

The critical component of the response with respect to both the treatment of individual patients and interaction with the community is clear communication about exposure levels and corresponding risk. ${ }^{4}$ In constructing a medical support system for

Table 3 Workers whose dose of exposure from the incident to February 2012 exceeded the annual limit*

\begin{tabular}{llll}
\hline Workers & $\begin{array}{l}\text { Exposed dose } \\
(\mathrm{mSv})\end{array}$ & $\begin{array}{l}\text { External exposure } \\
(\mathrm{mSv})\end{array}$ & $\begin{array}{l}\text { Internal exposure } \\
(\mathrm{mSv})\end{array}$ \\
\hline 1 & 678.08 & 88.08 & 590.00 \\
2 & 643.07 & 103.07 & 540.00 \\
3 & 352.08 & 110.27 & 241.80 \\
4 & 308.93 & 49.23 & 433.10 \\
5 & 475.50 & 42.40 & 433.10 \\
6 & 359.29 & 31.39 & 327.90 \\
\hline
\end{tabular}

* The annual dose limit was defined as $250 \mathrm{mSv}$ according to the Ordinance on Prevention of lonising Radiation Hazards in Japan. 


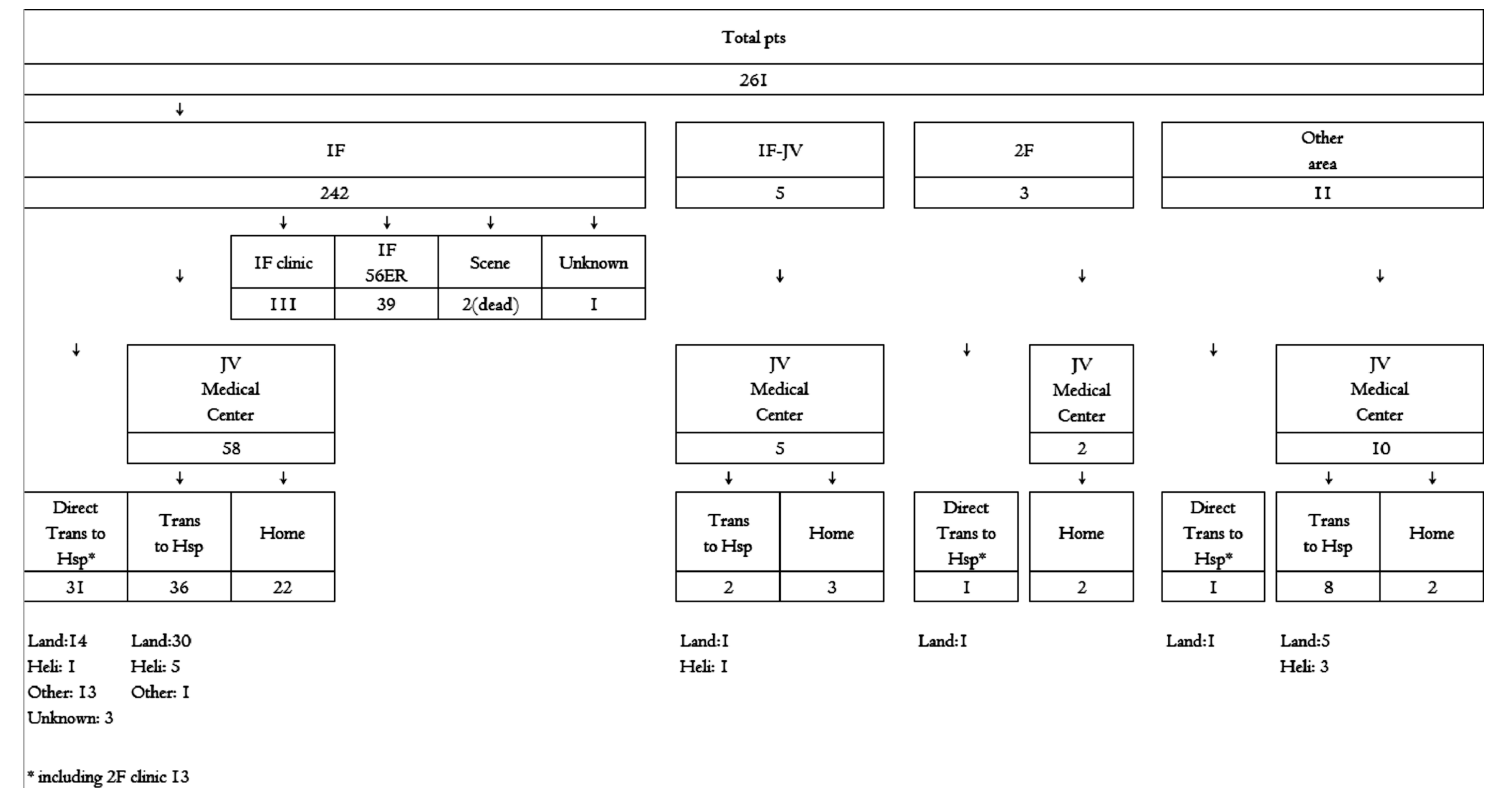

Figure 3 Actual flow of transport from patient examination to medical facilities. 1F, Fukushima Daiichi Nuclear Power Plant; 2F, Fukushima Daini Nuclear Power Plant; JV, J Village, 1F-JV, vicinities of 1F, 2F and JV; pts: patients; Land, land ambulance of Fire Department; Heli, emergency medical helicopter.

personnel engaged in restoration work, the most pressing point was our aim to create a system that could promptly and flexibly respond with an eye to both radiation emergency medicine and emergency/disaster medicine under conditions where the means of emergency transport and access to the site were limited and the functionality of the surrounding medical facilities was reduced. It goes without saying that, due to the environmental contamination brought on by the radiation, it was not possible to expect early improvements in accessibility or sufficient investment of emergency medical resources. We therefore sought to overcome these difficulties by allocating physicians with strong coordination abilities and the construction of a communication system that would make smooth coordination a reality. An expert in emergency/disaster medicine with knowledge of radiation medicine was sent to the OFC, while an expert in radiation emergency medicine with the ability to practise emergency/disaster medicine was sent to the JV. By constructing a strong communication and information system to connect the OFC with the relay bases on the frontlines centred round $1 \mathrm{~F}$ and the JV medical team, we sought to make smooth coordination a reality. After strategically distributing land lines, personal handyphone system (PHS), cell phones and MCA wireless, the patient flow that was formulated was considered to be a flow for coordinating prompt communication. Each day the OFC would directly telephone or conduct wireless communications with all relevant departments in accordance with the patient response flow and, by confirming the contact procedures and state of the equipment, ensured that the communication system could respond promptly in the event of sick or injured patients. Furthermore, the periodic simulation training led by the JV medical team is thought to have contributed greatly to the prompt response during the actual application. In addition, the operational improvements made while experiencing actual cases was the application of the PDCA (Plan-Do-Check-Act) cycle itself.

In an environment where collaboration between organisations in the framework of a vertically bound government and multiple agencies and institutions was certainly not seamless, participation of the members of the JAAM-which is a medical academic organisation-in the local system presented the opportunity to laterally integrate the physicians affiliated with the respective organisations from the perspective of specialisation. The benefits of this new system include the selection of medical facilities and transport according to the degree of emergency or severity of the patient's condition despite the limited modes of transport available and access to the site, as well as the ability to provide patients with decontamination/radiation survey functions at the JV Medical Center and the start of early examinations by a specialist in emergency medicine. Future tasks for the JAAM in responding to similar disasters are to offer opportunities for specialists in emergency medicine to increase their understanding of radiation medicine and to cultivate specialists in emergency medicine who are capable of coordinating with other organisations such as the government or Self-Defence Force. In addition to the efforts that must be given to the work to shut down the reactors, which will take place over the next several decades, consideration must also be given to our response, with a long-term perspective in the event of a new disaster at nuclear power plants throughout the country.

Contributors NM: data collection and analysis of off-site centre. YA: data collection and analysis of JV centre. YY, TS: planning the basic response for disaster. CT, KA: making a plan of cooperation with Fukushima local government. TA: chairperson of this project.

\section{Funding None.}

\section{Competing interests None.}

Provenance and peer review Not commissioned; externally peer reviewed.

Open Access Open Access This is an Open Access article distributed in accordance with the Creative Commons Attribution Non Commercial (CC BY-NC 3.0) license, which permits others to distribute, remix, adapt, build upon this work noncommercially, and license their derivative works on different terms, provided the original work is properly cited and the use is non-commercial. See: http:// creativecommons.org/licenses/by-nc/3.0/

\section{REFERENCES}

1 Tanigawa K, Hosoi Y, Terasawa S, et al. Lessons learned from the Fukushima Daiichi nuclear power plant accident; the initial 5 days medical activities after the accident (in Japanese). J Jpn Assoc Acute Med 2011;22:782-91.

2 http://radioactivity.mext.go.jp/old/ja/1270/2011/05/1305820_20110506.pdf (accessed 6 Oct 2012).

3 http://energy.gov/situation-japan-updated-8312 (accessed 6 Oct 2012).

4 Christodouleas JP, Forrest RD, Ainsley CG, et al. Short-term and long-term health risks of nuclear-power-plant accidents. N Engl J Med 2011;16;364:2334-41. 